\title{
MUNDUS - Um MMOG para instigar o conhecimento
}

\author{
Elisa Boff, Universidade de Caxias do Sul - eboff@ucs.br \\ Rafael Busetti, Universidade de Caxias do Sul - rbusetti@ucs.br
}

\begin{abstract}
Resumo. O uso de jogos na educação deve, além de atentar para o conteúdo e as estratégias pedagógicas, de questões lúdicas, de envolvimento, motivação e de interatividade. Este artigo apresenta a relação entre os ambientes de aprendizagem e os jogos educativos. O projeto do jogo MUNDUS, um MMOG (Massively Multiplayer Online Game), envolveu pesquisa de campo com alunos e professores, preocupação com a usabilidade do sistema, com as estratégias pedagógicas e com a flexibilidade de manutenção do conteúdo. A implementação do jogo é baseada em técnicas que levam a robustez e eficiência, bem como a apresentação aos usuários (aluno e professor) de três perfis de interface, a saber, o painel gerencial, a interface cliente (jogo) e o servidor que recebe as requisições do cliente.
\end{abstract}

Palavras-chave: jogo educativo, mmog, usabilidade em jogos, projeto de jogos educativos

\section{MUNDUS - A MMOG to instigate knowledge}

Abstract. The use of games in education should not only to attend to the content and to the pedagogical strategies. Issues of playful, engagement, motivation and interactivity are also very important. This article presents the relationship between learning environments and educational games. The MUNDUS' game design, a MMOG (Massively Multiplayer Online Game), has involved field research with students and teachers. It also has concerned about the usability of the system, with the educational strategies and the flexibility to maintain the content. The implementation of the game is based on techniques that lead to robustness and efficiency, as well as three different kind of interfaces, such as panel management, the client interface (game) and the server that receives client requests.

Keywords: educational game, mmog, game usability, educational game design

\section{Introdução}

Os ambientes virtuais de aprendizagem vem sendo projetados com especial atenção aos mecanismos de promoção da interação, com base em teorias que apresentam a aprendizagem como fruto do meio social (Vygostky, 1984) (Piaget, 1967) e (Maturana, 1995).

Através da utilização de jogos como ou através de um ambiente virtual de aprendizagem valemo-nos de recursos para o processo de ensino-aprendizagem que vão além da diversão e do entretenimento. Eles buscam, também, desenvolver habilidades e conhecimentos no jogador.

Segundo Bonjiolo (1998), “a fórmula computador mais jogo se torna perfeita, pois associa a riqueza dos jogos educativos com o poder de atração dos computadores. 
E, como consequência desta associação, teremos os jogos educativos computadorizados, onde o computador será usado de forma lúdica e prazerosa, para explorar um determinado ramo de conhecimento, além de trabalhar com algumas habilidades, como, por exemplo, destreza, associação de ideias e raciocínio lógico e indutivo, entre outras".

Com base em ideias de utilização de jogos e colaboração para o apoio a aprendizagem lúdica, este artigo apresenta um jogo que pode ser jogado por vários usuários, instigando o aluno a interagir, trocar ideias e experiências. Este jogo foi desenvolvido como um MMOG (Massively Multiplayer Online Game), ou Jogo Multiusuário Online de uso em massa, assim como o Second Life e Linden Lab ${ }^{2}$. Este tipo de jogo tem como principal característica um mundo virtual persistente onde os jogadores podem interagir entre si. Este mundo existe independente de usuários estarem conectados a ele ou não. Os jogadores podem criar um avatar, acessar o mundo, vagar pelo mapa, conversar com outras pessoas e até interagir com objetos.

O MMOG desenvolvido buscou oferecer ao professor liberdade para criar novos desafios aos jogadores e ainda poder consultar o andamento das atividades dos seus alunos através de relatórios.

Este artigo está organizado como segue. A seção 2 apresenta jogos educativos relacionados ao desenvolvido. A seção 3 apresenta o jogo MUNDUS, seu projeto e implementação. Por fim, são apresentadas as considerações finais e as referências utilizadas para redação deste artigo.

\section{Jogos para aprendizagem}

Os jogos educativos, ou edutainment (Education + Entertainment), associam educação com o entretenimento, criando experiências educativas que sejam divertidas.

Campos (1995) diz que os jogos educativos conseguem despertar no aluno diversos aspectos: motivação, curiosidade, estímulo, envolvimento no fato de querer aprender e cabe ao professor utilizar esses aspectos para criar estratégias pedagógicas. Assim, o aluno consegue enriquecer seu conhecimento de forma divertida. Dependendo dos recursos incluídos nos jogos, podem estimular o desenvolvimento de habilidades motoras, da cognição, da atenção, do autocontrole, do raciocínio lógico e da disciplina.

Os jogos devem fornecer ainda um ambiente pelo qual o jogador consiga se interessar. Um enredo envolvente, desafios, qualidade visual, recursos multimídia, metáforas adequadas, são elementos que mantêm o interesse do usuário. Além disso, a construção desse ambiente, percebido através da interface, deve prever uma interface limpa e prazerosa, a fim de melhorar a usabilidade (Nielsen, 2010) e a jogabilidade. Por isso, a questão de usabilidade de interface deve ser observada e atendida durante o projeto do jogo.

Um jogo no estilo MMOG consegue englobar diversas características, como a socialização entre os jogadores, cooperação, criatividade diante de suas ações, imersão no jogo, interatividade com outros jogadores, com os desafios e a interdisciplinaridade no momento em que ele pode acessar diferentes tipos de desafios.

Um exemplo de jogo do tipo MMOG é o Jeomm ${ }^{3}$. Este jogo é voltado para a educação utilizando arquiteturas organizacionais que existem nas escolas como disciplinas, notas, temas, avaliações, textos de explicação, entre outras. O mundo virtual

\footnotetext{
${ }^{1}$ http://secondlife.com/

${ }^{2} \mathrm{http}: / /$ lindenlab.com/

${ }^{3} \mathrm{http}: / /$ jeomm.unb.br/portal/
} 
consiste em replicar locais históricos, salas de aula, zoológicos. A ideia do jogo é replicar qualquer parte do mundo onde seja interessante para que o aluno possa adquirir experiências e aprender. $\mathrm{O}$ interessante deste projeto é que eles têm como objetivo criar um ambiente onde o mundo virtual possa ser construído por qualquer pessoa que deseja ajudar no projeto, onde qualquer parte do mundo pode ser constantemente atualizada.

O L.I.S. (Learning in the Space) de Mantovani (2000) é um jogo educativo cooperativo que promove a resolução de problemas, tomada de decisões e cooperação entre pares. Ele é destinado a alunos da $5^{\mathrm{a}}$ e $6^{\mathrm{a}}$ séries do ensino fundamental. O jogo é constituído por três missões: quiz, caça palavras e quebra-cabeça. O professor cria um jogo e então ele é designado como comandante, após isto, os alunos poderão acessar o jogo criado e serão os tripulantes. O comandante irá dividir os alunos em equipes, quando então é habilitado um Chat para os alunos poderem conversar. Quando a equipe estiver formada é escolhido então um capitão para fazer a interação com o software. $\mathrm{O}$ capitão então irá escolher entre três missões para começarem a responder. Quando concluídas as missões do jogo, é lançado um feedback para a equipe. O professor terá acesso a um editor, onde poderá fazer cadastro de diversos tipos de conteúdo para os jogadores jogarem.

O jogo Subindo e escorregando, de Bongiolo (1998), introduz o conceito de adição de números inteiros e é motivado pela ideia de estimular e gerar um ambiente de fascínio e sedução em torno de atividades que desafiem o aluno a pensar e criar soluções para os problemas apresentados. O ambiente visual é constituído por uma trilha e montanhas, onde o jogador irá jogar os dados para andar nesta trilha. $\mathrm{O}$ jogo possui dois dados, um azul e o outro vermelho. O vermelho caracteriza quantas casas ele deve avançar e o azul representa quantas casas ele deve recuar. Quando o jogador jogar os dados, ele deve fazer a operação entre um dado e o outro para saber em que casa ele deve ir. O jogo termina quando chegar na casa 10. Durante o jogo o aluno ainda pode pedir ajuda, onde irá para uma outra tela mostrando a operação e o resultado, quando o aluno voltar, o peão avança para a casa correta. O jogo, porém, não se caracteriza apenas por isso, existe ainda uma outra modalidade dentro dele que é a de desafios, que são perguntas e respostas exatas. Os desafios podem ser cadastrados pelo professor e são questões de múltipla escolha com resposta única.
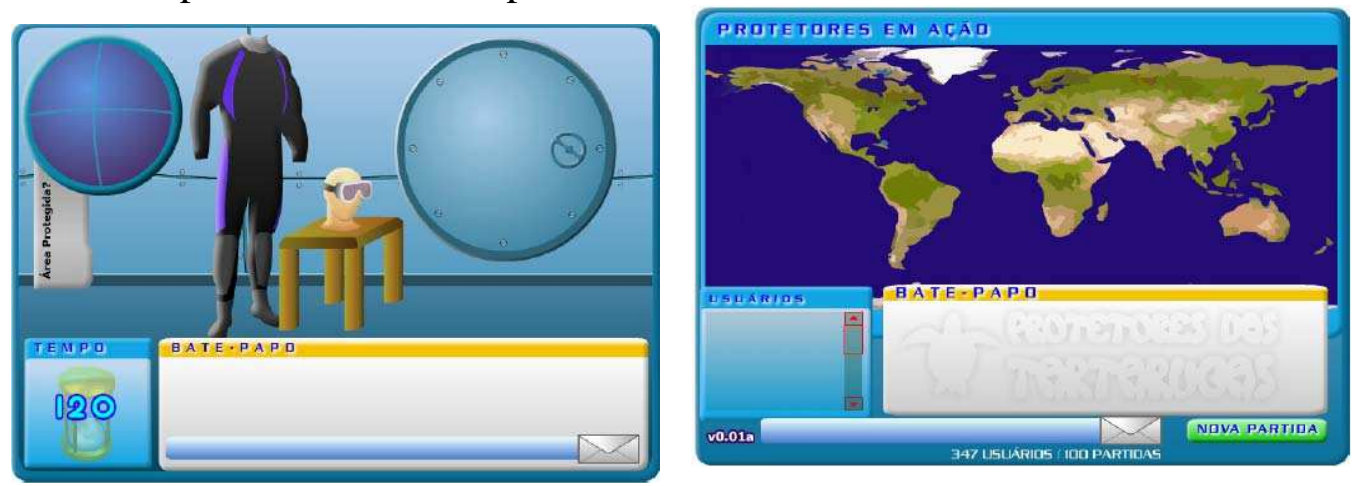

Figura 1: Jogo Protetores das Tartarugas

Silva (2008) desenvolveu o jogo "Protetores das Tartarugas" que transmite a sensação de que o jogador está dentro de um submarino (Figura 1), fazendo uma viagem. Quando o jogador conecta-se ao jogo ele encontra um mapa mundi com pontos onde existem submarinos esperando o embarque. Cada submarino pode possuir no máximo três jogadores, que podem se comunicar através do Chat. Dentro do submarino existe um radar que irá informar para um jogador que algo foi encontrado naquela região. $\mathrm{O}$ outro jogador, o mergulhador, terá que ir até o local e tirar fotos e trazer para o 
submarino e o terceiro jogador ficará com a responsabilidade de identificar qual a espécie encontrada nas fotos. Existem ainda predadores, onde os tripulantes do submarino devem usar um sonar para expulsá-los, neste momento existe uma interação entre elas para haver decisão em grupo. É possível ainda que o professor entre em cada submarino como "chefe de pesquisas" para avaliar o andamento do grupo e até mesmo direcioná-los.

A Tabela 1 apresenta uma comparação entre os softwares relacionados e, logo abaixo, a legenda associada aos resultados.

Tabela 1 - Comparação entre os jogos relacionados

\begin{tabular}{|c|c|c|c|c|c|c|c|c|}
\hline Jogo & $\begin{array}{l}\text { Conteú } \\
\text { do } \\
\text { Interdis } \\
\text { ciplinar }\end{array}$ & $\begin{array}{c}\text { Para } \\
\text { todas } \\
\text { as } \\
\text { idades }\end{array}$ & $\begin{array}{l}\text { Ambie } \\
\text { nte } \\
\text { Colabo } \\
\text { rativo }\end{array}$ & $\begin{array}{c}\text { Conteú } \\
\text { do } \\
\text { Manip } \\
\text { ulável }\end{array}$ & $\begin{array}{c}\text { Roda } \\
\text { na } \\
\text { Web }\end{array}$ & $\begin{array}{l}\text { Apresenta } \\
\text { conteúdo } \\
\text { multimídi } \\
\text { a (vídeo / } \\
\text { imagens) }\end{array}$ & $\begin{array}{l}\text { Free } \\
\text { ware }\end{array}$ & $\begin{array}{l}\text { Linguagem } \\
\text { Programaçã } \\
\text { o }\end{array}$ \\
\hline JEOMM & 3 & 1 & 1 & 1 & 1 & 1 & 1 & $\begin{array}{c}\text { Não } \\
\text { informado }\end{array}$ \\
\hline $\begin{array}{l}\text { Subindo e } \\
\text { Escorregando }\end{array}$ & 0 & 0 & 0 & 2 & 0 & 2 & 1 & $\begin{array}{c}\text { Não } \\
\text { informado }\end{array}$ \\
\hline $\begin{array}{l}\text { Learning in } \\
\text { the Space }\end{array}$ & 1 & 2 & 1 & 1 & 0 & 1 & 1 & $\begin{array}{c}\text { Não } \\
\text { informado }\end{array}$ \\
\hline $\begin{array}{l}\text { Protetores } \\
\text { das tartarugas }\end{array}$ & 0 & 3 & 1 & 0 & 1 & 1 & 1 & Flash \\
\hline Second Life & 1 & 1 & 1 & 1 & 0 & 1 & 1 & $\begin{array}{c}\text { Linden } \\
\text { Scripting } \\
\text { Language }\end{array}$ \\
\hline
\end{tabular}

\section{O jogo MUNDUS}

No projeto de um software específico como um jogo educativo devemos manter o foco no usuário do sistema. Se o jogador acessar um cenário desinteressante, em que os desafios não o fazem interagir e participar, teremos um jogo com conteúdo educativo e divertido, mas que não atingirá os objetivos de aprendizagem lúdica.

A fim de entender o público-alvo este trabalho realizou, na fase de análise do sistema e levantamento dos requisitos, uma pesquisa de campo com os professores e alunos. A pesquisa com os alunos obteve 74 respostas no período de um mês. A maioria das pessoas que responderam o questionário é do sexo masculino com cerca de $74 \%$.

Pelos resultados analisados, verificou-se que $26 \%$ não costumam jogar jogos eletrônicos, sendo que apenas 3\% realmente não se interessam por jogos que possam apresentar desafios. Percebemos então que a grande maioria se interessaria por um jogo educativo. Eles abordaram que o jogo deve apresentar desafios, que devem ficar mais difíceis e ao mesmo tempo o jogo deve ser divertido. A aprendizagem deve ficar como "pano de fundo", ou seja, será consequência do andamento do jogador no mundo. Muitos abordam que o jogo é uma forma de relaxar, por isso, se o jogo se torna maçante e repetitivo, eles não vão se interessar. Outro dado relevante é que $74 \%$ acham importante a formação de equipes durante o jogo para enfrentar os desafios, sendo que a principal forma de comunicação é através de chats. Mas esta não é a única forma em que o pessoal acha interessante, o áudio também, segundo eles, é um bom recurso para 
comunicação no momento em que estiverem imersos nos desafios. Poucos acharam importante o vídeo para comunicação, alguns até justificando que o vídeo pode tirar a concentração do jogador e o seu foco no desafio. Foi perguntando qual o cenário que seria mais interessante para que o jogo acontecesse. Os mais citados foram ambientes medievais, seguido de ambientes urbanos e florestas. No momento de criação do personagem, as principais características que foram ditas são cor da pele, tipo de cabelo, sexo e roupas. Muitos acham que quanto mais customizáveis, melhor, para poder transcrever suas características para seu personagem.

A pesquisa com os professores também foi realizada no período de um mês. Todos os professores acharam interessante que o conteúdo tivesse materiais relacionados, devido à complexidade de algumas questões e até mesmo para não frustrar o aluno. Em geral eles preferem links que direcionem o aluno para algum material, imagens e vídeos. Para apresentar o feedback ao aluno a maioria das respostas sugeriu o uso de texto. Uma outra forma abordada foi através de símbolos, onde cada símbolo poderia representar o acerto ou erro do aprendiz. No cadastro do desafio e suas respectivas perguntas, as informações devem ser diretas, além da classificação da grande área como, por exemplo, Matemática e Historia, e dos subtópicos. O sistema deve permitir o registro do nível de dificuldade para a questão. Quanto à questão de relacionar os desafios com senhas de acesso, muitos acharam desnecessários e qualquer um poderia ter o acesso a questão. Outros acharam que seria interessante para fazer uma tarefa para um determinado grupo ou até mesmo quando a turma apresenta diversos alunos de cursos diferentes, podendo então dar tarefas específicas a estes grupos.

Para a construção do relatório, os que responderam acham interessante o trajeto em que o aluno fez para as tarefas, como quais foram acessadas, quando os conteúdos relacionados foram visitados, as respostas corretas e incorretas. Outra questão levantada foi o tempo de resposta de cada pergunta e da seção em que o aluno entrou. Em geral a geração do $\log$ no sistema deve apresentar os desafios acessados, as perguntas acertadas e erradas. Os professores indicaram, em maioria, que a formação de equipe entre jogadores para responder os desafios seguindo o questionário é importante. Para o jogo instigar mais os alunos as sugestões foram de ter obstáculos para os alunos passarem para a próxima etapa, interfaces adequadas, atrativas e fáceis de usar.
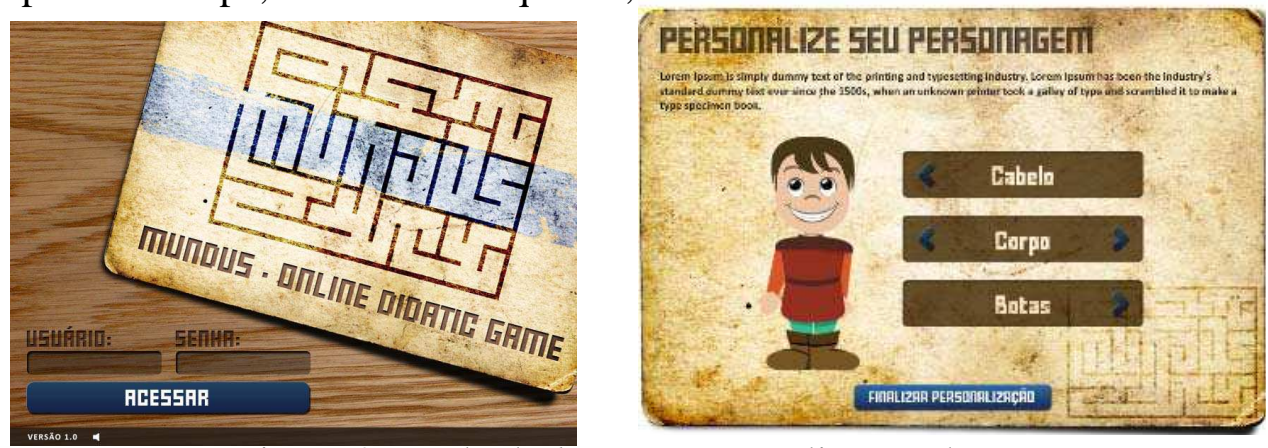

Figura 2 - Tela de login e personalização do personagem

Inicialmente os jogadores devem se autenticar no jogo e personalizar seu personagem definindo características como sua aparência (Figura 2). É possível selecionar o sexo, características físicas como cor do cabelo, tipo do cabelo e cor da pele e atribuir um nome a seu personagem. Depois de criado seu personagem o usuário terá o primeiro contato com o mundo (Figura 3), ele poderá interagir com os outros usuários neste ambiente através de um sistema de chat, ampliando a socialização entre os jogadores, um dos aspectos principais de um ambiente colaborativo conforme Mantovani (2000). 


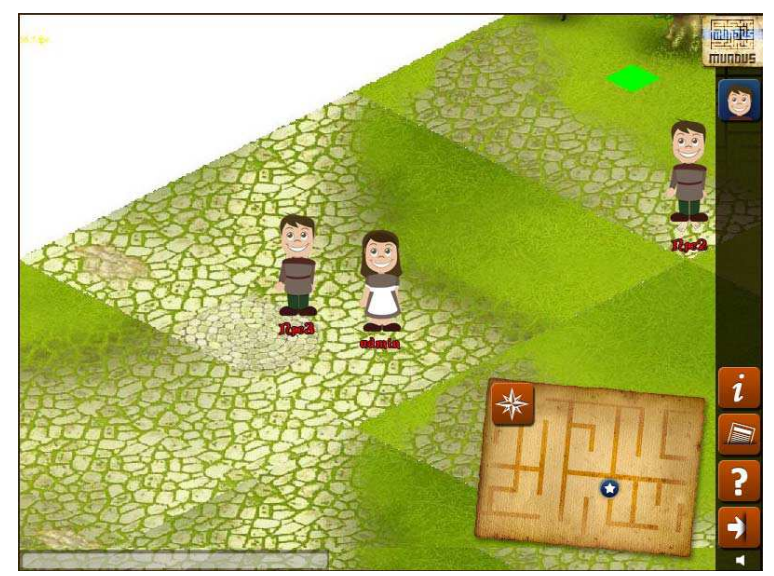

Figura 3 - Mundo (ambiente principal do jogo)

O jogo apresenta desafios aos jogadores e conforme o seu andamento o jogador vai adquirindo mais experiência para enfrentar outros novos desafios. Estes desafios são cadastrados pelo professor, no painel de administração, e são organizados (Figura 4) por assuntos (grandes áreas) e por subtópicos em diferentes salas (ou mundos).
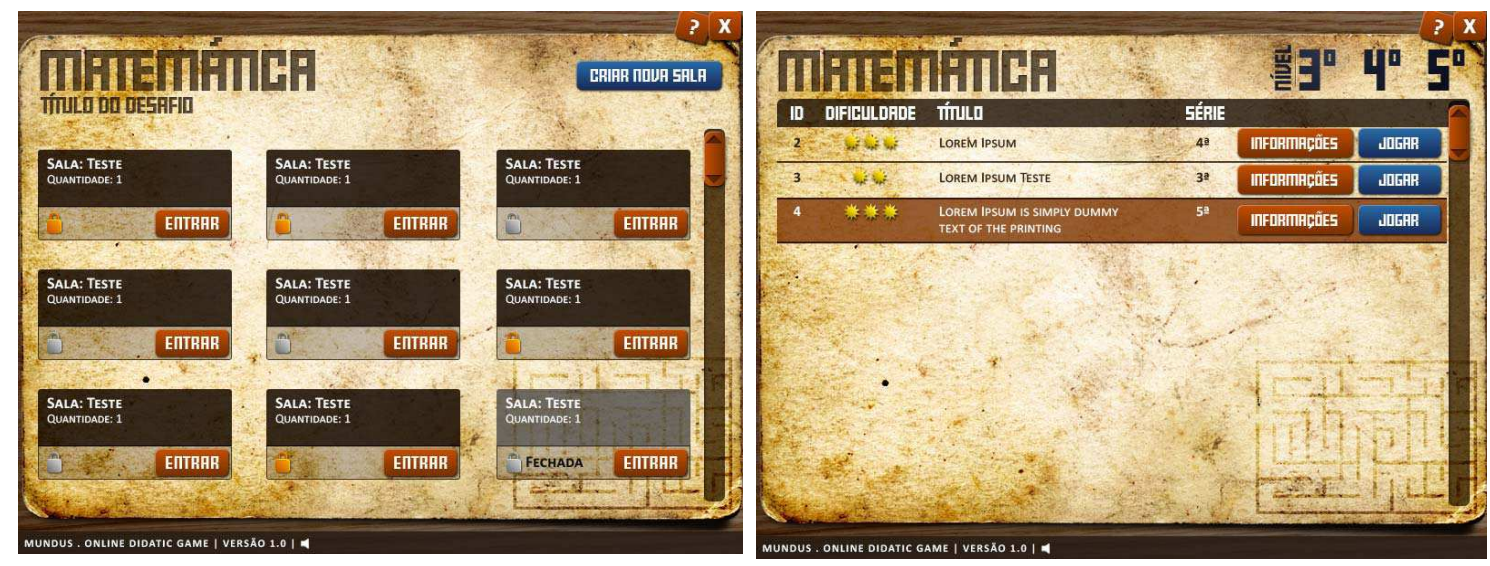

Figura 4 - Escolha do desafio a ser jogado

No momento em que o jogador está no mundo, ele precisa explorar o local, investigar onde podem estar os outros jogadores e buscar onde estão os desafios para resolver. Jonassen (1996) e Baranauskas (1999) falam que a investigação e a descoberta estimulam ainda mais o jogador dentro do ambiente, motivando-o a continuar e então se envolvendo ainda mais efetivamente. Para fornecer um suporte maior a esta investigação, exploração, curiosidade e motivação, este jogo apresenta um mapa do mundo (detalhe da Figura 3) para que o jogador tenha uma visão global da navegação.

O jogador tem autonomia para escolher os locais que ele deseja ir e os desafios os quais deseja responder.

Apoiado na teoria de Zona de Desenvolvimento Proximal de Vygotsky (1984), o professor pode desenvolver questões que busquem desenvolver o nível potencial do jogador. Isso porque os desafios que compõem a base de conhecimento do jogo não são predefinidos, eles podem ser constantemente atualizados através do painel de gerenciamento pelo professor.

Para cada desafio podem ser adicionados conteúdos complementares 
relacionados ao tópico do desafio (Figura 5). Estes conteúdos relacionados poderão ser vídeos, imagens e links para textos, e servirão como subsídio para os alunos construírem seu conhecimento.

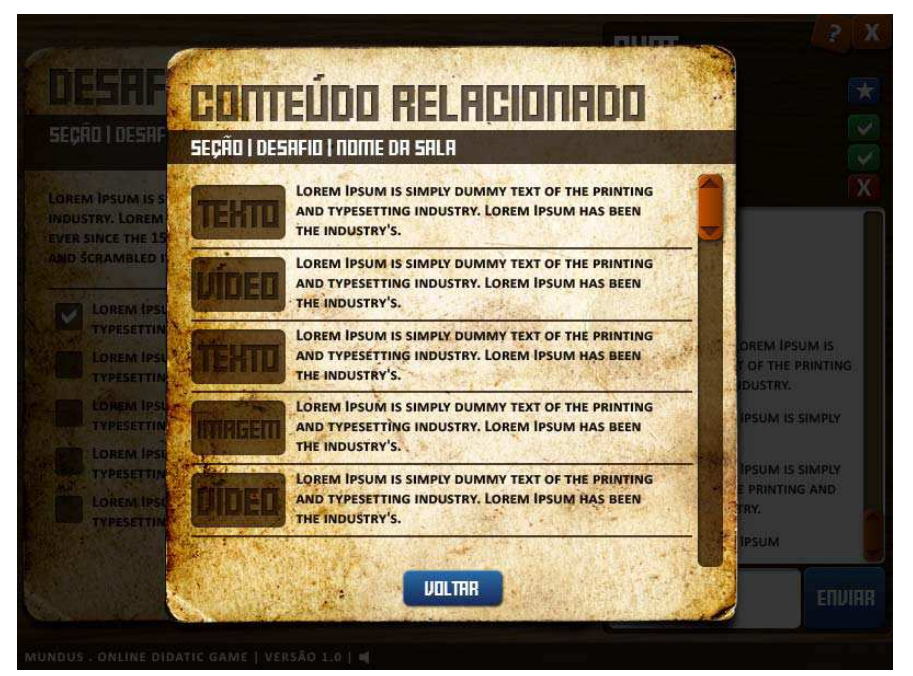

Figura 5 - Apresentação de conteúdos relacionados ao tópico do jogo

Os professores podem criar salas com acesso restrito a fim de compor grupos, como uma turma (Figura 6). Um aluno pode convidar colegas para a mesma sala de desafio e interagir com eles através do sistema de chat. A fim de manter os alunos motivados, a cada desafio vencido o aluno ganha "experiência". É importante ressaltar que a cada pergunta respondida, o sistema oferece um feedback para o aluno, fazendo com que o aluno entre num processo de reflexão sobre sua resposta e até mesmo para a formação de uma nova idéia. Valente (1993) abordou que "O processo de achar e corrigir o erro constitui uma oportunidade única para o aluno aprender sobre um determinado conceito envolvido na solução do problema ou sobre estratégias de resolução de problemas".

No painel de administração os professores podem emitir relatórios para acompanharem o processo de formação do conhecimento dos jogadores. O jogador também pode emitir um relatório de seu andamento.

Por fim, o jogo fornece um ranking dos melhores jogadores do jogo, em função da experiência adquirida nos desafios respondidos. 


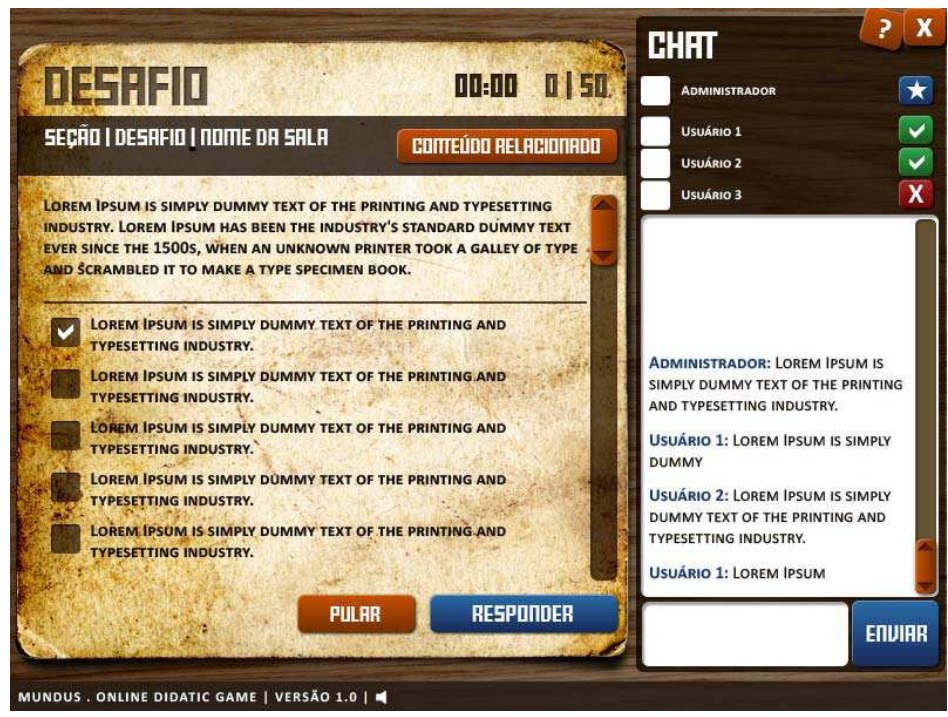

Figura 6 - Desafios resolvidos colaborativamente por um grupo

\subsection{Tecnologias utilizadas no desenvolvimento do MUNDUS}

A criação de um ambiente de aprendizagem colaborativo, através de um jogo do estilo MMOG, necessita de uma arquitetura que contemple toda a especificidade da aplicação. Algumas APIs ${ }^{4}$ foram utilizadas para facilitar o desenvolvimento do jogo, e também um middleware para construção do servidor do jogo e para a comunicação entre os jogadores.

O painel de gerenciamento e a aplicação cliente (jogo propriamente dito) foram desenvolvidos em uma arquitetura de três camadas. A camada de interface é a que permite a interação entre usuário e o jogo. Nesta camada não há regras de negócio e acesso direto aos dados. A camada intermediária, que apresenta as regras de negócio, recebe as requisições da camada de interface, processa as informações e quando necessário faz acesso aos dados. A última camada é responsável pela persistência dos dados, onde foi utilizado um banco de dados para armazenamento das informações, como usuários do sistema, professores e os desafios. Esta última camada recebe as requisições apenas da camada de negócio.

A linguagem empregada para desenvolvimento do jogo e para a construção do painel é o Actionscript $3^{5}$. Ela é uma linguagem de programação que está especificada no padrão internacional ECMA-262 $2^{6}$, além de possuir suporte a outras tecnologias como XML, Webservices e Javascript. Um jogo educacional graficamente rico também deve garantir a portabilidade em diferentes sistemas operacionais e, inclusive, na Web. Neste contexto, a tecnologia Flash apresenta uma boa alternativa para atender essas necessidades, pois fornece suporte multiplataforma e é multibrowser.

No início do ano de 2009, o Flash Player ${ }^{7}$ trouxe diversos recursos consigo, porém o que mais chamou atenção foi a adição do eixo $\mathrm{Z}$ nativamente em seus objetos visuais, facilitando ainda mais o desenvolvimento de ambientes que simulam o 3D.

A camada de negócio do jogo foi construída na linguagem Actionscript e para

\footnotetext{
${ }^{4}$ Application Programming Interface

${ }^{5} \mathrm{http}: / /$ www.actionscript.org/

${ }^{6}$ European Computer Manufacturers Association 262

${ }^{7} \mathrm{http}: / / \mathrm{www}$. adobe.com/br/products/flashplayer/
} 
persistência de dados foi utilizada a linguagem PHP $^{8}$ com a extensão PDO (PHP Data Object).

O painel de administração foi desenvolvido em tecnologia Flex ${ }^{9}$. Ele estabelece comunicação com as outras camadas para validar as informações e persistir os dados na base de dados MySQL ${ }^{10}$.

Tanto o jogo como o painel de administração precisam acessar a base dos dados MySQL. A tecnologia definida para fazer esta comunicação é o AMFPHP que usa o protocolo $\mathrm{AMF} 3^{11}$, que provê a comunicação binária entre as tecnologias e possui também compactação de dados para realizar a transferência dos dados de forma mais rápida.

O servidor mantém o estado do ambiente sempre atualizado, a fim de permitir o acesso dos jogadores. O mundo é persistente, ou seja, informações sobre os objetos, posições e personagens são armazenados. A comunicação entre cliente e servidor se dá através de sockets e, por isso, o middleware utilizado na implementação deste jogo foi o SmartFoxPro Server ${ }^{12}$, que é um servidor socket multiplataforma desenvolvido em linguagem Java e que pode ser utilizado no Flash. Ele possui uma API que facilita a programação da aplicação cliente (jogo), tendo suporte a linguagem AS3.

\section{Considerações finais}

Este artigo apresentou o processo de desenvolvimento de um MMOG, utilizado como ferramenta educativa tanto para os mestres quanto para os aprendizes.

O jogo educativo desenvolvido nesta pesquisa levou em consideração questões relacionadas a aprendizagem do aluno, a usabilidade do sistema, a qualidade dos gráficos e a portabilidade da aplicação. Uma decisão importante de projeto foi não definir uma base de conhecimento estática, ou seja, que não possa ser alterada e ampliada. $\mathrm{O}$ objetivo é que os professores assumam o papel de gestor do conhecimento do aluno, elaborando diferentes desafios que estimulem a formação do conhecimento através de colaboração, da interação e do estabelecimento de relações entre assuntos afins.

Quando o aprendiz estiver interagindo com o jogo, ele estará formulando suas hipóteses com base em seu conhecimento, nos feedbacks fornecidos pelo ambiente, nos conteúdos ou nas interações com outros jogadores. Este cenário de equilíbrio e desequilíbrio remete a Piaget e é uma das bases de formação do conhecimento do jogador.

Um jogo educativo deve possuir um roteiro bem elaborado, um visual atrativo, diversidade de interação e personagens bem formulados. Sendo assim, mantemos a motivação e a diversão dos jogadores. O jogo ainda pode trazer o desenvolvimento de habilidades como concentração, resolução de problemas, colaboração com os outros jogadores e tomada de decisões.

Foi possível constatar que o desenvolvimento de um jogo educativo, sobretudo multiplayer, é realmente complexo em função da sua natureza interdisciplinar, pois envolve questões técnicas de programação, pedagógicas, psicológicas, e direção de arte.

\footnotetext{
${ }_{9}^{8}$ http://br.php.net/

${ }^{9} \mathrm{http}: / / \mathrm{www}$.adobe.com/products/flex/

${ }^{10} \mathrm{http}: / / \mathrm{www} . \mathrm{mysq1.com/}$

${ }^{11}$ Actionscript Message Format

$12 \mathrm{http}: / / \mathrm{www}$. smartfoxserver.com
} 


\section{Referências}

Battaiola, A. L., Elias, N. C. e Domingues, R. G. et al Desenvolvimento de um Software Educacional com Base em Conceitos de Jogos de Computador In: XIII Simpósio Brasileiro de Informática na Educação. São Leopoldo: SBC, 2002.

Baranauskas, M. C. C., Rocha, H. V., Martins, M. C., D`Abreu, J. V. V. Uma taxonomia para usos do computador em educação. In: VALENTE, J. A. O Computador na Sociedade do Conhecimento. Brasília: Proinfo-SED Ministério da Educação, Governo Federal, 1999.

Bongiolo, C. E. F. et al. Subindo e Escorregando: jogo para introdução do conceito de adição de números inteiros. In: Congresso da rede iberoamericana de informática na educação, 1998.

Campos, M de B. Hiperhistórias na Educação: Um meio de educação/reeducação psicomotora. In: VI Simpósio Brasileiro de Informática na Educação. Anais. Florianópolis: SBC-UFSC, 1995.

Jonassen, D. O Uso das Novas Tecnologias na Educação a Distância e a Aprendizagem Construtivista. Brasília: Em Aberto, ano 16, n. 70, abr/jun, 1996.

Mantovani, A. M. et al. L.I.S. - Learning in the Space: Ambiente de Aprendizagem Computacional Cooperativo. In: Congresso Iberoamericano de Informática Educativa, 5, 2000, Viña del Mar, Chile: Ribie, 2000.

Maturana, H., Varela, F. (1995) Árvore do conhecimento. Ed. Psy, Campinas, 1995.

Nielsen, J. Heuristic Evaluation. Capturado em Julho de 2010. Online. Disponível na Internet em: http://www.useit.com/papers/heuristic. Julho, 2010.

Piaget, J.. A Psicologia da Inteligência. Lisboa: Fundo de Cultura, 1967.

Silva, F. M. Protetores das Tartarugas - um ambiente virtual colaborativo para a educação ambiental. In: IV Seminário Jogos eletrônicos, educação e comunicação. Salvador, 2008.

Valente J. A. Computador e Conhecimento: repensando a educação. Campinas: Gráfica UNICAMP, 1993.

Vygotsky, L. V. A formação social da mente: desenvolvimento dos processos mentais superiores. São Paulo: Martins Fontes Editora Ltda,1994. 